\title{
Synthesis and Characterization of Poly (ester-amide) of Adipic Acid and Fatty Amide of Melia Azedarach Seed Oil - An Eco-friendly Resource
}

\author{
Abul Hasnat*, Sageer Ahamad, Syed Aziz Ahmad \\ Natural Product and Polymer Research Laboratory, Department of Chemistry, G.F. College (Affiliated to M.J.P. \\ Rohilkhand University) Shahjahanpur, U.P. 242001, India \\ E-mail: hasnatgfc@rediffmail.com
}

\begin{abstract}
Synthesis of polymeric materials from renewable resources has attracted the attention of researcher worldwide as they are not only reducing the dependency on petrochemicals, a finite resource but also friendly to the environment. Synthesis of valuable polymers from non-conventional and non-edible vegetable oils solves the problem of waste disposal as well as bringing down the cost of end products. Melia azedarach seed oil (MASO), a non-traditional, non-edible and abundantly available resource is utilized for the synthesis of poly (ester-amide) (MAPEAA) by the aminolysis with diethanolamine followed by step-growth polymerization with adipic acid. The MAPEAA polymeric resin was characterized by physic-chemical analyses as per standard reported laboratory methods. The structural elucidation of the resin was carried out by spectral analyses. Physicomechanical and chemical/corrosion resistance performances of the resin were also investigated.
\end{abstract}

Keywords: Melia azedarach seed oil, renewable resource, vegetable oil, Poly (ester-amide)

\section{Introduction}

There have been potential demands worldwide for replacing petroleum based raw materials with the renewable ones [1-3]. This is quite significant from the societal and environmental points of view. Among different renewable resources vegetable oils obtained from seeds of various plants are in the spotlight of the chemical industries as they are the abundantly available in nature and also show low eco-toxicity as well as low-toxicity towards humans [4,5]. Common traditional seed oils such as linseed, sunflower, castor, soybean, coconut are being largely used in the synthesis of polymers like alkyds, epoxies, polyurethanes, interpenetrating polymer networks (IPN)s, poly (ester- amide)s and many others [4,6-10]. These polymers are extensively used as coatings, adhesives, insulators and biomedical structures. However, among afore mentioned traditional oils some of them possess medicinal values and are edible too [11,12]. Therefore, it is important to explore the gift of the nature and utilize the non-edible and non-conventional seed oils as starting raw materials for the development polymers, which ultimately reduce the demands of conventional vegetable oils.

Melia azedarach belongs to the family meliaceae largely cultivated in rural areas due to its valuable wood $[13,14]$. The seeds of plants contain about 40-wt \% triglyceride oil with sufficiently high iodine value, which provide the film formation ability to the synthesized polymers $[13,14]$. Meagre utilization of Melia azedarach seed oil, especially in the polymer syntheses encourages us to utilize this triglyceride oil in the synthesis of poly(ester-amide) using adipic acid as a dibasic acid [14-16].

Poly (ester-amide)s of vegetable oil origin are amide modified alkyds and have hybrid properties of both functionalities pendent amide and repeating ester; consequently show better performances than normal alkyds in terms of hardness, water vapor resistance and corrosion resistance [9,12]. In present work efforts have been made to synthesize the poly (ester-amide) resin through poly (condensation) reaction between adipic acid and fatty amide diol of Melia azedarach seed oil obtained by amidation of triglyceride oil with diethanol amine. The synthesized polymeric resin has been characterized by measuring the physico-chemical properties as per standard laboratory methods and spectral analyses. 


\section{$2 \quad$ Experimental}

\subsection{Materials}

The oil was extracted from the dried and crushed seeds of Melia azedarach (collected from the different places of the Shahjahanpur district, U.P., India) through the soxhlet apparatus using petroleum ether as a solvent $\left(60-80{ }^{\circ} \mathrm{C}\right)$. The physic-chemical characterizations of the Melia azedarach seed oil were performed as per standard reported methods and were reported elsewhere [14]. Adipic acid, diethyl ether, methanol, xylene were used of analytical grade (Merck-India). Diethanol amine of analytical grade procured from the S.D. Fine Chemicals, India and was distilled under reduced pressure before use.

\subsection{Syntheses}

\subsubsection{N,N-bis (2-hydroxyethyl) Melia azedarach oil fatty amide (HEMAFA)}

HEMAFA was synthesized and characterized as per previously reported method [14].

\subsubsection{Melia azedarach Poly (ester-amide) of Adipic Acid (MAPEAA)}

Melia azedarach Poly (ester-amide) of adipic acid (MAPEAA) was synthesized by the poly (condensation) polymerization reaction between HEMAFA and adipic acid. HEMAFA and adipic acid in equal molar ratio along with xylene as solvent were placed in a four necked round bottom flask fitted with a Dean-stark trap, a thermometer, water condenser and a mechanical stirrer. Reaction mixture was heated upto $180{ }^{\circ} \mathrm{C}$ with continuous stirring and allowed to continue under same condition till the required acid value. The progress of reaction was monitored by taking the acid values at regular intervals and also by measuring the water collected in Dean-Stark trap [12]. After the completion of reaction, the reaction content was allowed to cool at room temperature under continuous stirring and the product was taken out from the reaction flask. The excess of solvent was removed using a rotary vacuum evaporator under reduced pressure to obtain MAPEAA.

\subsection{Characterization}

Physico-chemical characterizations like specific gravity, refractive index, iodine value, hydroxyl value, saponification value of the samples were performed as per standard laboratory methods $[12,17]$. The structural elucidation of the polymer samples were carried out by FT-IR spectrometer (Perkin-Elmer Cetus instruments) using $\mathrm{NaCl}$ cell. ${ }^{1} \mathrm{H}-\mathrm{NMR}$ and ${ }^{13} \mathrm{C}-\mathrm{NMR}$ spectra were recorded on JEOL GSX 300 MHz FX-1000 spectrometer using deuterated chloroform as a solvent and tetramethyl silane (TMS) as an internal standard.

\subsection{Preparation of Coatings}

Coatings of MAPEAA polymeric resin were prepared on mild steel strips, $70 \times 25 \times 1 \mathrm{~mm}$ size for pysicomechanical test and 30x10x1 mm size for chemical/corrosion resistance test. The mild steel strips were polished on various grade of silicon carbide papers, then washed with distilled water, degreased with alcohol and carbon tetrachloride $[17,18]$. They were dried under vacuum for several hours. The coatings were developed on these specimens by brush technique using solution of $60-w t \%$ of resin. Coated strips were baked at $175{ }^{\circ} \mathrm{C}$ for 20 minutes. The coated specimens were evaluated for bending test on $1 / 8$ " conical mandrel, the resistance to scratch hardness (BS 3900), and impact resistance (IS: 101 part $5 /$ Sec.31988) tests. Chemical and corrosion resistance tests of the polymeric films were carried out in water, acid $(3-\mathrm{wt} \% \mathrm{HCl})$, alkali $(2-\mathrm{wt} \% \mathrm{NaOH})$ and salt $(3.5-\mathrm{wt} \% \mathrm{NaCl})$ by placing them in 3 in. diameter porcelain dishes, in aforementioned media. Periodic examinations were carried out at regular intervals until coating showed visual evidence of softening, deterioration in gloss, discoloration or weight loss (Table 1). 
Table 1. Physico-chemical, mechanical and chemical/corrosion resistance properties of MAPEAA.

\begin{tabular}{ll}
\hline Test & MAPEAA \\
\hline & \\
Physico-chemical analyses & \\
Color value & 8.0 \\
Specific gravity & 0.948 \\
Refractive index & 1.5058 \\
Acid value (mg KOH/gm) & 9.8 \\
Iodine value & 41.48
\end{tabular}

Physico-mechanical properties

$\begin{array}{ll}\text { Bending test }(1 / 8 \text { in }) & \text { Passes } \\ \text { Gloss at } 45^{\circ} & 32 \\ \text { Impact resistance }(\mathrm{lb} / \mathrm{in}) & 100 \\ \text { Scratch hardness }(\mathrm{Kg}) & 1.0\end{array}$

Chemical/corrosion resistance*

$\mathrm{H}_{2} \mathrm{O}$ (10 days) $\mathrm{C}$

$\mathrm{HCl}(3-\mathrm{wt} \%) 10$ days $\quad \mathrm{C}$

$\mathrm{NaOH}(2-\mathrm{wt} \%) 2 \mathrm{hrs} \quad \mathrm{B}$

$\mathrm{NaCl}(3.5-\mathrm{wt} \%) 10$ days $\quad \mathrm{B}$

Xylene 10 days $\quad \mathrm{C}$

$* \mathrm{~A}=$ Film detached; $\mathrm{B}=$ Film partially detached; $\mathrm{C}=$ Loss in gloss; $\mathrm{D}=$ Slight loss in gloss; $\mathrm{E}=$ Unaffected

\section{$3 \quad$ Results and Discussion}

Figure 1 illustrates the reaction scheme for the synthesis of MAPEAA polymeric resin. The MAPEAA was obtained by the poly (condensation) of bi-functional monomers; HEMAFA (diol) and adipic acid (dibasic acid) in 1:1 molar ratio. The polymeric reaction proceeded through the poly(condensation)s of carboxyl and alcoholic groups to form ester moieties without scissoring of polyester chain [19]. The byproduct water was removed from the reaction mixture as azeotrope with the help of Dean-Stark trap to facilitate the esterification [20,21]. Progress of the polymerization was monitored by determining the acid values at regular intervals and the same was further confirmed by the collection of equivalent amount of water in Dean-Stark trap. At the end of reaction acid value was found to be $9.8 \mathrm{mg}$ $\mathrm{KOH} /$ gram; using the principle of end group analyses it has been envisaged to the average ratio of terminal carboxylic group and repeating ester linkage is 1:16.

The FT-IR spectrum of MAPEAA shows the broad band at $3414 \mathrm{~cm}^{-1}$ for the terminal $-\mathrm{OH}$ groups, bands for asymmetric and symmetric $\mathrm{CH}_{2}$ group at $2928 \mathrm{~cm}^{-1}$ and $2855 \mathrm{~cm}^{-1}$ respectively. The appearance of band at $1762 \mathrm{~cm}^{-1}$ for the carbonyl of ester in addition to band at $1642 \mathrm{~cm}^{-1}$ of the carbonyl of amide, confirms the formation of ester linkage [22].

The ${ }^{1} \mathrm{H}-\mathrm{NMR}$ spectrum of MAPEAA shows the peaks for the protons of double bonded carbons of fatty amide chain at $\delta=5.38-5.52 \mathrm{ppm}$, while protons of $\mathrm{CH}_{2}$ adjacent to oxygen of ester at $\delta=4.62$ ppm. $\mathrm{CH}_{2}$ attached to nitrogen of fatty amide appears at $\delta=3.28-5.46 \mathrm{ppm}$, allylic protons between double bonds appear at $\delta=2.38 \mathrm{ppm}, \mathrm{CH}_{2}$ adjacent to carbonyl of est er at $\delta=2.24-2.34 \mathrm{ppm}$. Broad peak for chain $\mathrm{CH}_{2}$ of fatty amide appears at $\delta=1.18-1.38 \mathrm{ppm}$ and protons of terminal $\mathrm{CH}_{3}$ appear at $\delta$ $=0.84 \mathrm{ppm} .{ }^{13} \mathrm{C}-\mathrm{NMR}$ spectrum of MAPEAA shows the peak for carbonyl of ester at $\delta=172.6 \mathrm{ppm}$ in addition to carbonyl of amide at $\delta=162.4 \mathrm{ppm}$. Double bonded carbons of fatty amide appear at $\delta=$ 126.4-126.2 ppm. $\mathrm{CH}_{2}$ adjacent to oxygen of ester appear at $\delta=53.2 \mathrm{ppm}$, allylic $\mathrm{CH}_{2}$ appear at $\delta=43.2$ ppm, adipic acid and fatty amide chain $\mathrm{CH}_{2}$ appear at $\delta=32.6-22.8 \mathrm{ppm}$, whereas terminal methyl carbon appear at $\delta=13.2$. ppm [23,24]. 


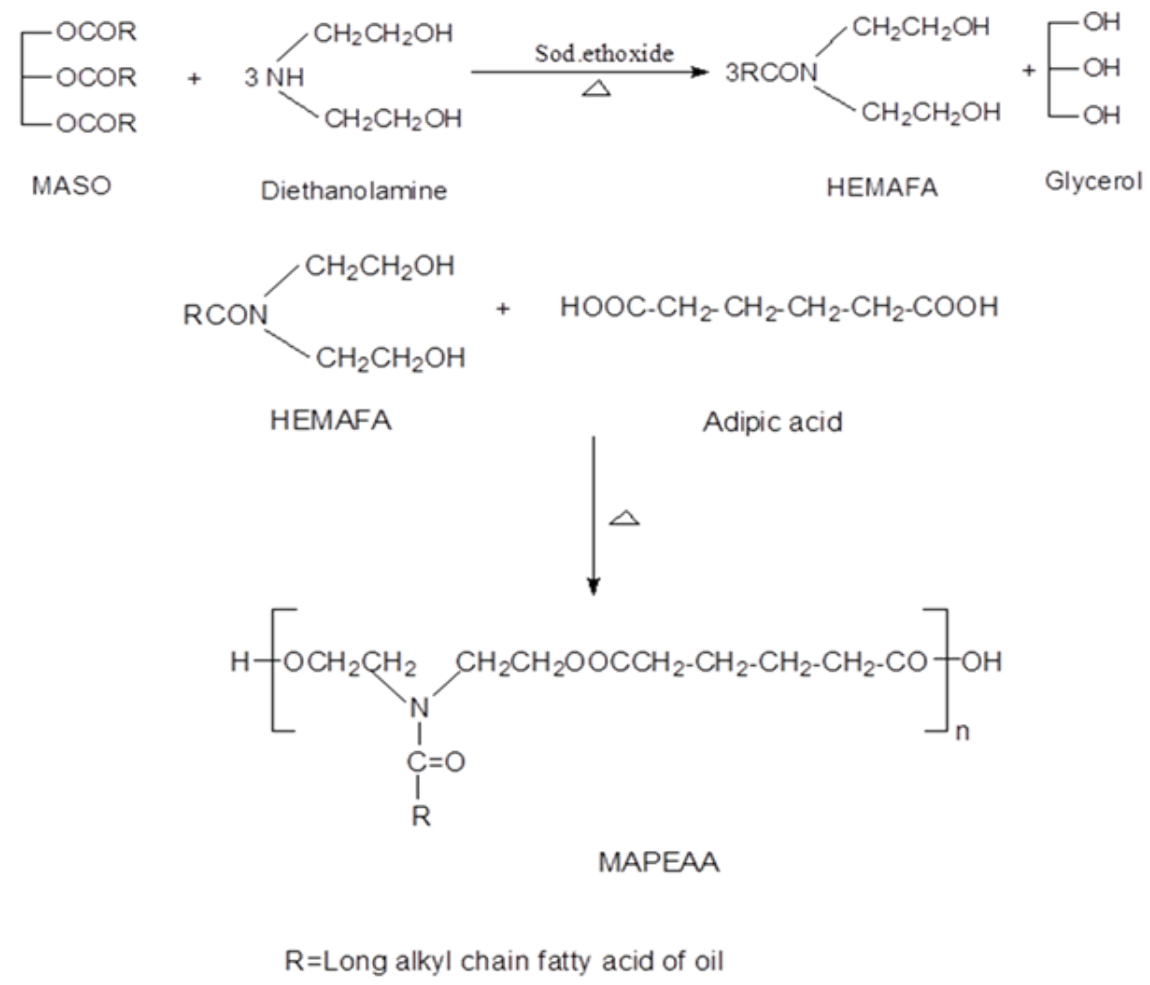

Figure 1. Reaction scheme for the synthesis of MAPEAA.

\subsection{Film Properties}

The films of MAPEAA polymeric resin were prepared on the mild steel strips to investigate the film characteristic like flexibility, resistance to scratch, impact resistance, gloss and chemical/corrosion resistance (Table 1). Samples of MAPEAA polymeric resins pass the impact resistance more than 100 $\mathrm{lb} /$ in as well as scratch hardness $1.0 \mathrm{~kg}$. These are reasonably due to presence of both pedant amide and repeating ester linkages; they not only confer adhesion towards metals surface but also improve attraction between the polymeric chains [7,16]. Polymeric film of MAPEAA passes the bending test on1/8" conical mandrel, no visual crack was observed. Table 1 indicates that chemical resistance ability of MAPEAA polymeric resin was fairly good in xylene, water, acidic and salty solutions. This is reasonably due to presence of long fatty amide chain which imparts the hydrophobic character to the final product $[24,25]$.

\section{Conclusion}

From this study it can be concluded that the non-edible, non-traditional and annually renewable Melia azedarach seed oil can be utilized successfully for the synthesis of MAPEAA polymeric resin. The synthesized resin was characterized by physico-chemical analyses and spectroscopic studies. Physicomechanical and corrosion/chemical resistance properties of the polymeric films were investigated. The results indicate that MAPEAA has well prospective of coating materials. The synthesis of MAPEAA, therefore gives a profitable utilization of MASO, rot away at the various plantations in each season.

Acknowledgments. The authors would like to thank the authorities of G. F. College, Shahjahanpur, UP, India for providing necessary facilities to carry out this study and Dr. A. Moheman for valuable suggestions. 


\section{References}

1. S. Ahmad, S. M. Ashraf, A. Hasnat, S. Yadav and A. Jamal, "Studies on urethane-modified alumina-filled polyesteramide coatings cured at ambient temperature," Journal of appliedpolymerscience, vol. 82, pp. 1855-1865, 2001.

2. S. H. Ansari,A. Hasnat and S. A. Ahmad, "Synthesis and characterization of methyl(methacrylate) modified polyesteramide," Orientaljournal of chemistry, vol. 28, pp. 1015-1018, 2012.

3. N. B. Samarth andP.A. Mahanwar, "Modified vegetable oil based additives as a future polymeric materialreview," Open journal of organic polymer material, vol. 5, pp. 1-22, 2015.

4. F. S.Guner, Y. Yagci and A. T. Erciyes, "Polymers from triglyceride oil," Progress in polymers science, vol. 31, pp. 633-670, 2006.

5. G. Lligadas, J.C. Ronda, M. Galia and V.Cadiz, "Renewable polymeric materials from vegetable oils: a perspective," Materials today, vol. 16, no. 9,pp, 337-343, 2013.

6. C. O. Akintayo,K. O. Adebowale, "Synthesis and characterization of acrylated Albizia benth medium oil alkyds," Progress inorganic coatings, vol. 50, pp. 207-212, 2007.

7. S. Ahmad, S. M. Ashraf,A. Hasnat and A. Noor, "Studies on epoxidised oil and its blend with polystyrene and poly(methyl methacrylate )," Indian journal of chemicaltechnology, vol. 8, pp. 176-180, 2001.

8. M. R. Islam, M.D.H. Beg and S. S.Jamari, "Development of vegetable-oil-based polymers," Journal of applied polymer science, vol. 131, pp. 40787-40799.

9. S. H. Ansari, G. Imran, M. Naseem,S. A. Ahmad and A. Hasnat, "Synthesis and characterization of urethane modified polyesteramide," Oriental journal ofchemistry, vol. 28, pp.607-612, 2012.

10.F. Zafar, S. M. Ashraf andS. Ahmad, "Studies on zinc-containing linseed oil based polyesteramide,"reactiveE functional polymers, vol. 67, pp. 928-935, 2007.

11. S. Ahmad, S. M. Ashraf, F. Naqvi, S. Yadav and F. Zafar,"Alumina -incorporated polyesteramide from nonedible seed oils," Journal of macromolecular science part A: pure and applied chemistry, vol. 43, pp. 1409-1419, 2006 .

12. S. Ahmad, S. M. Ashraf, F. Naqvi, S. Yadav andA. Hasnat, "A polyesteramide from Pongamia glabra oil for biologically safe anticorrosive coating," Progress in organic coatings, vol. 47, pp. 95-102, 2003.

13. S. P. Ambastha, "Useful plants of India," CSIR, New Delhi, 1986.

14. S. Ahamad, S. A. Ahmad andA. Hasnat, "Synthesis and characterization of styrenated poly (ester-amide) resin from Melia azedarach seed oil-an eco-friendly resource," Chemical science transactions, vol. 4, no. 4, pp. 10471053, 2015.

15. S. Ahamad, G. Imran, S. A. Ahmad andA. Hasnat, "Synthesis and characterization of polyesteramide urethane derived from Melia azedarach seed oil," Oriental journal chemistry,vol. 31,no.2,pp. 1169-1173, 2015.

16. S. Ahamad, G. Imran, S. A. Ahmad andA. Hasnat, "Studies on acrylic acid modified poly(ester-amide) resin from Melia azedarach seed oil- a renewable resource, "Chemical science transactions, vol. 4, no. 3,pp. 858-864, 2015.

17. K. J. Sounders, "Organic polymer chemistry", $2^{\text {nd }}$ edn., Chapman and Hall, USA, 1988.

18. S. Yadav, F. Zafar, A. Hasnat andS. Ahmad, "Poly(urethane fatty amide) resin from linseed oil-a renewable resource," Progress in organic coatings, vol. 64, pp. 27-32, 2009.

19. S. Ahmad, S. M. Ashraf, S. N. Hassan and A. Hasnat, "Synthesis, characterization and performance evaluation of hard anticorrosive coating materials derived from diglycidyl ether of bisphenol A acrylate and methacrylate," Journal of applied polymer science, vol.95, pp. 494-501, 2005.

20. P. Bahadur and N. V. Sastry, "Principles of polymer science," $1^{\text {st }}$ edn., Narosa Publishing House, India, 2003.

21. F. W. Billmeyer, "Text book of polymer science", $3^{\text {rd }}$ edn., John Wiley \& Sons, (Asia) Pte, Ltd., Singapure, 2007.

22. R. M. Silverstein, G. C. Bassler and T. C. Morril, "Spectroscopic identification of organic compounds," $5^{\text {th }}$ edn., John Wiley \& Sons, New York, 1991.

23. G. M. Lampman, D. L. Pavia, G. S. Kriz and J. R. Vyvyan, "Spectroscopy," $4^{\text {th }}$ edn., Cenage learning, U.S., 2012 .

24. M. Alam, S. M. Ashraf, A. R. Ray, andS. Ahmad,"Development of anticorrosive poly(ether-urethane) amide coatings from linseed oil, a sustainable resource," Journal ofpolymerand environment, vol. 18, pp. 208-215, 2010. 
25. S. Ahmad, S. M. Ashraf, F. Naqvi, S. Yadav and A. Hasnat, "A polyesteramide from Annona sequamosa oil for anticorrosive coating," Journal of polymer materials, vol. 18, pp. 53-60, 2001. 